\title{
Regeneration and Transformation via Agrobacterium tumefaciens of Echinacea purpurea L.
}

\author{
Moemen Hanafy ${ }^{1}$, Usama I. Aly and Mohamed A. Matter \\ Plant Biotechnology Department, National Research Centre, El-Behooth Str., Dokki, \\ Cairo, Egypt
}

Key words: Echinacea purpurea, Regeneration, A. tumefaciens, Transformation

\begin{abstract}
Leaf explants of Echinacea purpurea L. taken from aseptically germinated seedlings were inoculated with $A$. tumefaciens strains EHA105, carrying a binary vector conferring herbicide resistant bar gene and fungal resistant chitinase gene. Glufosinate ammonium-resistant shoots were regenerated on a medium containing BAP and NAA at a concentration of 4.88 and $0.053 \mu \mathrm{M}$, respectively. A subsequent transfer of shoots to medium containing BAP was necessary for stem elongation and leaf development. Transgenic Echinacea plants carrying bar and chitinase genes were selected for their resistance to glufosinate ammonium herbicide. Molecular analysis using PCR confirmed the integration of the transgenes into plant genome. This is the first report on genetic transformation of Echinacea plant using bar gene as a selectable marker.
\end{abstract}

\section{Introduction}

Echinacea purpurea L. is a group of purple coneflowers in the family Asteraceae. It has been used traditionally as an herbal medicine and dietary supplements for hundreds of years (Percival 2000). In recent years, the purple coneflower has gained global attractiveness due to it's beneficially effect on human's immune system (Bauer and Wagner 1991). Extracts from the plant have shown antioxidative, antibacterial, antiviral and antifungal properties, and are used in the treatment of the common cold, as well as respiratory and urinary diseases (Grimm and Muller 1999, Barrett 2003). Recent technological advances have allowed researchers to analyze some of the medicinally active compounds present in Echinacea sp. and to speculate on their modes of action (Choffe et al. 2000). Complex polysaccharides, such as arabinogalactane and xyloglucan, extracted from the roots of different Echinacea spp. have been found to stimulate

\footnotetext{
${ }^{1}$ Author for correspondence. Institute of Plant Genetics, Plant Biotechnology Department, Leibniz University Hannover, Herrenhauser Str. 2- 30419 Hannover, Germany. <mshanafy@yahoo.com>
} 
mammalian immune systems (Coeugniet and Elek 1987) and to act as antiinflammatory agents (Tragni et al. 1988). In the middle of the 20th century, Echinacea sp. was introduced as a medicinal plant to Europe (Bauer et al. 1991, Bauer 1998).

Many approaches that were unfeasible to implement by customary genetics can now be realized through transgenic techniques. Regeneration through tissue culture is a critical step for efficient transformation of most plants. However, in some species the lack of an efficient regeneration method is a huge impediment to employ the transformation technology (Penna et al. 2002). Developing protocols for efficient genetic transformation of medicinal plants with unique metabolic pathways, is important to understand the molecular basis and regulation of secondary metabolism in plants and to engineer them for specific metabolites (Pandey et al. 2010). Though transformation of a number of agriculturally important plant species has been reported, such efforts on medicinally important plants have been very few (Gómez-Galéra et al. 2007)

Despite the importance of Echinacea and abundant pharmacological and clinical studies, information concerning tissue culture and genetic transformation is quite rear. Recently, Echinacea species have been regenerated from a range of tissues from in vitro seedlings to mature, field-grown plants (Abbasi et al. 2007). Tissue culture of Echinacea can play a vital role in the development of novel germplasm, rapid multiplication, and genetic modifications for enhanced potential active compounds production. In vitro propagation and regeneration from petiole explants of E. purpurea have been established (Choffe et al. 2000). Moreover, axillary buds, adventitious shoots and somatic embryos have been used for in vitro mass propagation of four commercially important Echinacea species, including E. angustifolia, E. pallida, E. paradoxa, and E. purpurea (Lakshmanan et al. 2002).

Recovery of transgenic Echinacea plants via Agrobacterium-mediated transformation using neomycin phosphotransferase II (nptII conferring kana-mycin resistance) as a selectable marker has been reported (Koroch et al. 2002; Wang and To 2004). Transformed hairy root cultures of Echinacea purpurea was established by infecting different types of explants with three type strains of Agrobacterium rhizogenes (Wang et al. 2006). In this study a new protocol for Agrobacterium-mediated transformation of E. purpurea using bar gene which confers tolerance to herbicide $\mathrm{BASTA}^{\circledR}$, as a selectable marker has been developed.

\section{Materials and Methods}

Seeds of Echinacea purpurea L. were secured from Floriculture Department, Faculty of Agriculture, Cairo University. Echinacea seeds were surface sterilized 
by a solution containing $2.36 \%(\mathrm{w} / \mathrm{v})$ sodium hypochlorite for $20 \mathrm{~min}$ and washed thoroughly with sterilized distilled water. The sterilized seeds were then germinated on basal medium containing MS salts and $0.7 \%$ agar. The $\mathrm{pH}$ value of the medium was adjusted to 5.8 . The cultures were incubated in $25^{\circ} \mathrm{C}$ growth chamber under light conditions of $16 \mathrm{hr}$ per day. Within four weeks of cultivation, the in vitro growing Echinacea plantlets reached about $6-8 \mathrm{~cm}$ in height and used in further regeneration and transformation experiments.

Shoot tips and leaves were cut into small segments and inculcated on MS supplemented with different combinations of NAA and BAP. Cultures were incubated in the same pervious conditions for two months. Regenerated shoots (3 - $4 \mathrm{~cm}$ in height) were rooted on MS supplemented with different concentrations of IBA in the range of $4.92-14.76 \mu \mathrm{M}$.

An effective concentration of PPT for the selection of transformed shoots was determined by culturing non-transformed leaf explants (control) on MS supplemented with $4.88 \mu \mathrm{M} B A+0.053 \mu \mathrm{M}$ NAA and contains different concentrations of PPT $(0,0.5,1.0,1.5,2.0,2.5,3$ and $4 \mathrm{mg} / \mathrm{l})$.

The cultures were transferred twice to the same medium added with the same level of herbicide at two weeks intervals and were scored for the number of surviving explants. The herbicide was added to the media after autoclaving.

The dual-binary vector system pGreenII/pSoup was used in the present work (Hellens et al. 2000). The T-DNA contains the bar gene fused between nos promoter and terminator sequences of $A$. tumefaciens as a selectable marker and a heterologous chitinase gene (Chit30) from Streptomycies olivaceoviridis ATTCC11238 (Fig. 1). The chimeric chitinase gene was cloned via PCR based method into pGreenII binary vector 0229 under constitutive double $35 \mathrm{~S}$ promoter

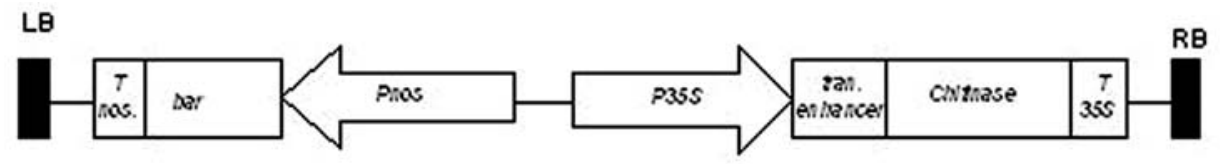

Fig. 1. Schematic structure of the T-DNA region of the transformation vector used for Echinacea transformation. Pnos, promoter sequence of the nopaline synthase gene; Tnos, terminator sequence of the nopaline synthase gene; P35S, 2x35S promoter of cauliflower mosaic virus; tran. enh. Translation enhancer; T35S, terminator sequence of cauliflower mosaic virus; $R B$ and $L B$, right and left borders, respectively, of the T-DNA region. The construct is not shown to scale.

from cauliflower mosaic virus (Provided by Hans-Joerg Jacobsen and Fathi Hassan, Leibniz University Hannover, Germany). The bar gene encodes a phosphinothricin acytyltransferase (PAT) enzyme which confers resistance to bialaphos and the related compounds phosphinothricin (PPT), the active ingredient of herbicide BASTA $^{\circledR}$ and gulfosinate ammonium, through acetylation. Young leaves were used as the explants for transformation experiments. A. tumefaciens strain EHA105 (Hood et al. 1993) harboring the 
transformation vector, was cultured in LB liquid medium supplemented with 50 $\mathrm{mg} / \mathrm{l} \mathrm{kanamycin.} \mathrm{Bacterial} \mathrm{cultures} \mathrm{were} \mathrm{grown} \mathrm{on} \mathrm{an} \mathrm{orbital} \mathrm{shaker} \mathrm{at} 28^{\circ} \mathrm{C}$ until OD600 $=1.0$. Agrobacterium cells were harvested by centrifugation at $8000 \mathrm{xg}$ for $10 \mathrm{~min}$ and re-suspended in liquid cocultivation MS $(4.88 \mu \mathrm{M}$ BAP and $0.053 \mu \mathrm{M}$ NAA).

Explants were soaked in Agrobacterium suspension for $30 \mathrm{~min}$ and blotted dry before culturing on solid cocultivation medium for two days. After cocultivation, the explants were washed thoroughly in sterile distilled water containing $400 \mathrm{mg} / \mathrm{l}$ cefotaxime. The explants were then transferred to a selection medium containing MS $+4.88 \mu \mathrm{M}$ BA, $0.053 \mu \mathrm{M}$ NAA, $300 \mathrm{mg} / \mathrm{l}$ cefotaxime and 2 $\mathrm{mg} / \mathrm{l}$ glufosinate ammonium and they were sub-cultured at two-week intervals to eliminate the bacteria growth and stimulate shoot regeneration. After about one month of culture, the explants started to regenerate. The shoots were excised and transferred to BA-containing medium for shoot elongation. Well developed shoots were transferred to rooting medium.

The genomic DNA was extracted from transformed and non-transformed Echinacea plantlets using a modified CTAB method Sul and Korban (1996). PCR analysis was conducted with the following primers, bar447-F: 5'GATTTCGGTGACGGGCAGGA-3', bar447-R: 5' TGCGCTCGGTACGGAAGTT$3^{\prime}$, with a predicted product size of $447 \mathrm{bp}$. For amplification of the A. tumefaciens picA chromosomal locus, the following primers were used: picA-1,5'ATGCGCATGAGGCTCGTCTTCGAG-3' and picA-2, 5'GACGCAACGCATCCTCGATCAGCT-3' (Rong et al 1991), with a prediction product size of $550 \mathrm{bp}$.

Denaturation at $94^{\circ} \mathrm{C}$ for $4 \mathrm{~min}$ followed by 30 amplification cycles $\left(94^{\circ} \mathrm{C} / 60 \mathrm{~s}\right.$, $60^{\circ} \mathrm{C} / 60$ s (bar) or $65^{\circ} \mathrm{C} / 60$ s (picA), $72^{\circ} \mathrm{C} / 60 \mathrm{~s}$ ) and final extension step at $72^{\circ} \mathrm{C}$ for $10 \mathrm{~min}$. The PCR products were visualized by running the completed reaction on a $1 \%$ agarose gel containing ethidium bromide. Pictures were taken under UV light. Meanwhile the plasmid was used as positive control.

\section{Results and Discussion}

Leaf and shoot tip explants prepared from in vitro germinated seedlings of Echinacea were assessed for multiple shoot regeneration on cytokinin-containing medium. Since BAP was found to be the most effective and widely used cytokinin in several plants species including Echinacea, alone or in combination with auxin (Koroch et al. 2002, Mechanda et al. 2003, Koroch et al. 2003, Sauve et al. 2004, Gockel et al. 1992, Harbage 2001), it was chosen to induce multiple shoot formation from shoot tip and leaf explants on MS supplemented with BAP alone at a concentration of 4.4 and $8.87 \mu \mathrm{M}$. After 4 weeks of cultivation the explants produced adventitious shoot (Fig. 2). Addition of NAA $(0.053 \mu \mathrm{M})$ and 
BAP $(4.88 \mu \mathrm{M})$ to MS was the most effective, providing shoot regeneration for 93.5\% of leaf explants and the highest number of shoots per explant (2.685). On the other hand, the same medium providing $52.75 \%$ of shoot regeneration for shoot tip explants with 1.52 shoots per explant (Table 1). For length of shoots, it was found that shoots produced from the shoot tip explants were longer than ones comes from leaf explants $(4.86$ and $3.81 \mathrm{~cm})$ respectively. Increasing NAA concentration resulted in increased callus production and low shoots initiation (data not shown). It is clear however that leaf explants were more competent for regeneration than shoot tip explants.
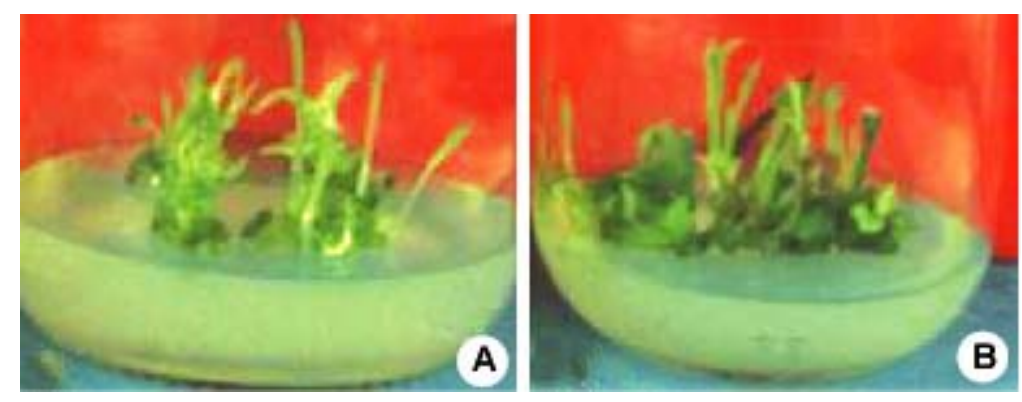

Fig. 2. Direct regenerated plantlets derived from leaf (A) and shoot tip (B) explants of $E$. purpurea cultured for two months on MS supplemented with $0.053 \mu \mathrm{M}$ NAA and 4.88 $\mu \mathrm{MBAP}$.

Table 1. Morphogenetic response of Echinacea purpurea explants after two months cultivation on MS fortified with $0.053 \mu \mathrm{M}$ NAA and $4.88 \mu \mathrm{M}$ BA.

\begin{tabular}{lccc}
\hline Explant & $\begin{array}{c}\text { Frequency of shoot } \\
\text { formation }(\%)\end{array}$ & $\begin{array}{c}\text { Number of shoots per } \\
\text { explant }\end{array}$ & $\begin{array}{c}\text { Shoot length } \\
(\mathrm{cm})\end{array}$ \\
\hline Shoot tip & $52.75 \pm 9.71$ & $1.52 \pm 0.066$ & $4.86 \pm 0.355$ \\
Leaf & $93.5 \pm 11.84$ & $2.685 \pm 0.133$ & $3.81 \pm 0.282$ \\
\hline
\end{tabular}

Each value represents the mean $\pm \mathrm{SE}$ of four replicates.

Root formation is an obligatory phase for micropropagation of plants produced in vitro. Some of them initiate roots without special treatments while others require a medium supplemented with different growth regulators essentially of an auxin nature. Different plant species might vary in their requirement of auxin type for adventitious root formation. Shoots produced from either leaf or shoot tip explants of Echinacea were cultured on MS supplemented with different concentration of IBA $(0.0,4.92,9.84$ and $14.76 \mu \mathrm{M})$. Data showed that, shoots come from both leaf and shoot tip explants gave roots on MS-basal medium after one month of incubation (Table 3). Increasing IBA concentrations resulted an increasing in root length (Table 2). Shoots come from leaf explants 
had roots longer than ones come from shoot tip. Using IBA at a concentration of $14.76 \mu \mathrm{M}$ gave the best result $(5.0 \mathrm{~cm})$. In previous reports, plant

Table 2. Effect of different concentrations of IBA on root development of in vitro regenerated shoots derived from shoot tip (ST) and leaves (L), of Echinacea purpurea.

\begin{tabular}{|c|c|c|c|c|c|c|}
\hline \multirow[t]{2}{*}{$\begin{array}{c}\text { IBA } \\
(\mu \mathrm{M})\end{array}$} & \multicolumn{2}{|c|}{$\begin{array}{l}\text { Frequency of root } \\
\text { formation (\%) }\end{array}$} & \multicolumn{2}{|c|}{$\begin{array}{c}\text { Number of } \\
\text { roots }\end{array}$} & \multicolumn{2}{|c|}{$\begin{array}{l}\text { Root length } \\
\quad(\mathrm{cm})\end{array}$} \\
\hline & ST & $\mathrm{L}$ & ST & L & ST & $\mathrm{L}$ \\
\hline Control & $14.25 \pm 2.85$ & $18.25 \pm 4.27$ & $1.5 \pm 1.55$ & $2.0 \pm 0.19$ & $0.2 \pm 0.02$ & $0.3 \pm 0.04$ \\
\hline 4.92 & $38.25 \pm 7.27$ & $52.5 \pm 9.01$ & $2.2 \pm 0.64$ & $4.5 \pm 0.58$ & $0.5 \pm 0.04$ & $1.1 \pm 0.09$ \\
\hline 9.84 & $47.0 \pm 6.98$ & $73.75 \pm 9.55$ & $3.0 \pm 0.91$ & $6.75 \pm 0.64$ & $0.8 \pm 0.06$ & $2.7 \pm 0.41$ \\
\hline 14.76 & $51.0 \pm 7.71$ & $89.0 \pm 12.72$ & $4.15 \pm 1.49$ & $7.5 \pm 0.92$ & $1.0 \pm 0.09$ & $5.0 \pm 0.91$ \\
\hline
\end{tabular}

Each value represents the mean \pm SE of four replicates.

regeneration from petiole explants of E. purpurea was achieved by using only a small amount of BAP (Choffe et al. 2000), whereas, in the present study, BAP in combination with NAA was most effective in inducing adventitious shoot regeneration from leaf explants. Response of leaf explant to BAP and NAA concentrations in the media could be a reflection of probable differences of endogenous hormonal levels in the explant sources or different tissue sensitivities to these plant growth regulators (Lisowska and Wysonkinska 2000). All shoots longer than $1.5 \mathrm{~cm}$ were transferred to rooting medium for root development. The survival rate of regenerated plantlets transferred to soil was $95 \%$.

In view of the fact that the selection of transformed cells is a prerequisite to facilitate shoot regeneration, the choice of selectable marker gene, selective agent, and timing of application is a key step in this process. The selectable marker bar gene of Streptomyces hygroscopicus encodes phosphinothricin acetyl-transferase (PAT), which inactivates phosphinothricin (PPT); It is the ammonium salt of glufosinate, the active component of BASTA by acetylation (Thompson et al. 1987). Therefore, glufosinate ammonium (PPT) was used to select the Echinacea transformed plants during tissue culture.

A gradual decrease in survival explants was observed in leaf explants cultured on increasing concentration of PPT (data not shown). PPT was found to be lethal at concentration of $16.56 \mu \mathrm{M}$, as it completely inhibited regeneration as well as survival of the explants; hence, this concentration was applied for the selection of transformed shoots. Herbicide-based selection of transformants has led to the successful recovery of transgenic plants such as Pisum sativum (Schroeder et al. 1993, Bean et al. 1997), Glycine max (Zhang et al. 1999), Lupinus 
species (Pigeaire et al. 1997) and Trifolium subterranean (Khan et al. 1994), faba bean (Hanafy et al. 2005), rice (Wenefrida et al. 2007), sweet potato (Yi et al. 2007), Sedum erythrostichum (Yoon et al. 2002).
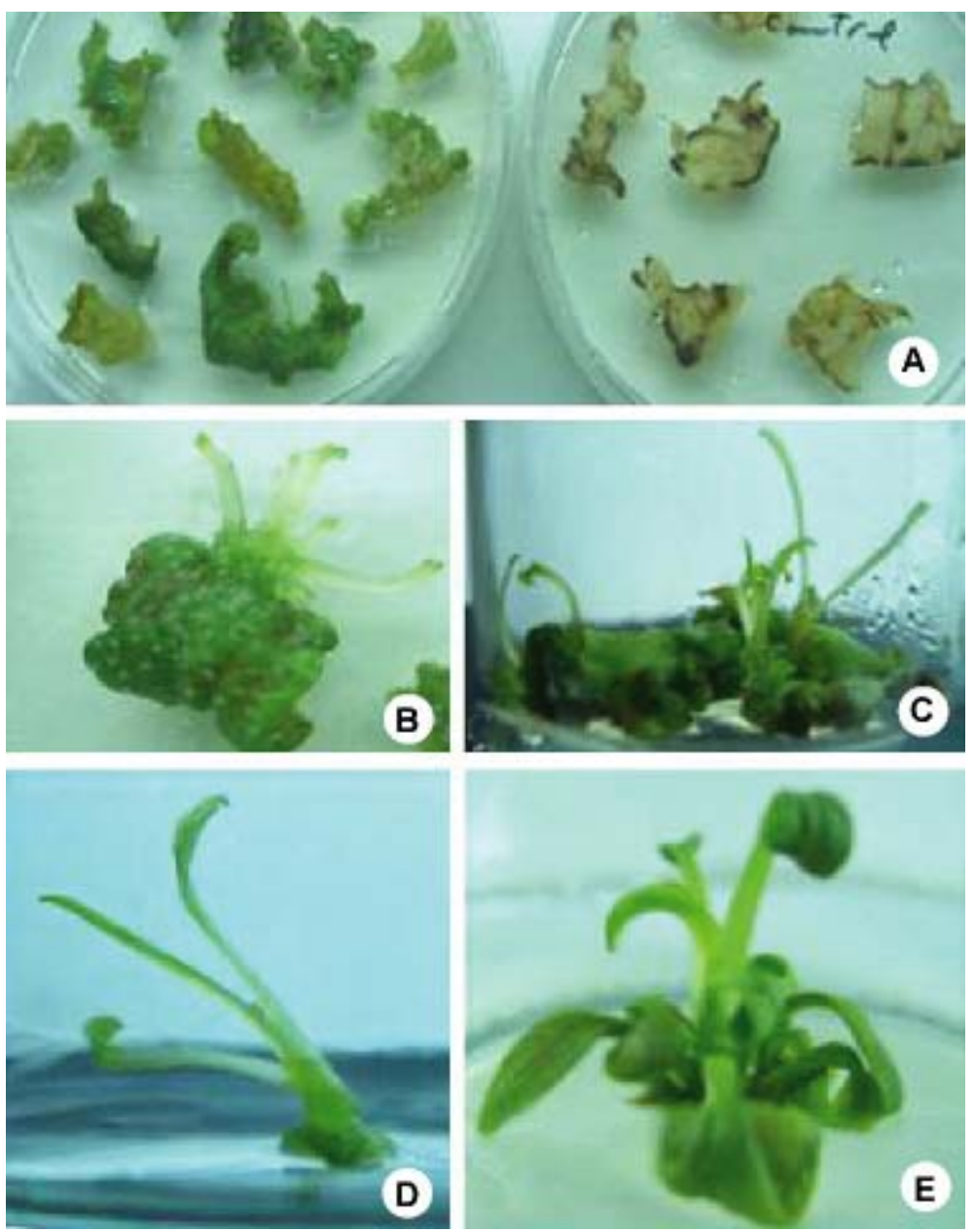

Fig. 3. Plant regeneration of Echinacea purpurea at different stages of the transformation procedure: A. leaf explants were excised from in vitro grown plantlets, transformed by A. tumefaciens and cultured on Petri dishes containing selection medium supplemented with $16.56 \mu \mathrm{M}$ PPT and 828.33 $\mu \mathrm{M}$ cefotaxim (right plate is untreated (control) explants). B. A late stage of shoot bud formation from leaf explants. C. A typical culture showing formation of calli and differentiated shoots. D. Elongated shoots cultured on PPT free medium. E. A typical regenerated transgenic shoots.

In series of transformation experiments with Echinacea the explants (leaf) were inoculated with Agrobacterium strain EHA105 containing a transformation vector harboring Chit and bar genes, selection was done by $16.56 \mu \mathrm{M}$ PPT. After three - four weeks of culturing on selective medium, all control explants had died. On the other hand, a number of Agrobacterium treated explants started to regenerate (via organogenesis) and about 3 - 4 shoots appeared from each explant 
on the regeneration medium. A higher percentage of regenerated shoots was obtained from leaf explants cocultured three days in the dark with Agrobacterium and then further cultured in the selection medium for up to three months. Subsequently the regenerated shoots were transferred onto MS medium containing $\mathrm{BAP}$ at a concentration of $4.88 \mu \mathrm{M}$ for stem elongation and leaf development. The shoots selected for 2 - 3 months were transferred to rooting medium. Several independent transformants have been regenerated but due to the low growth of the regenerated shoots we recovered only 5 independent clones and further analyzed by PCR. Schematic representation for in vitro regeneration and Agrobacterium-mediated transformation of E. purpurea from leaf explants is shown in Fig. 3.

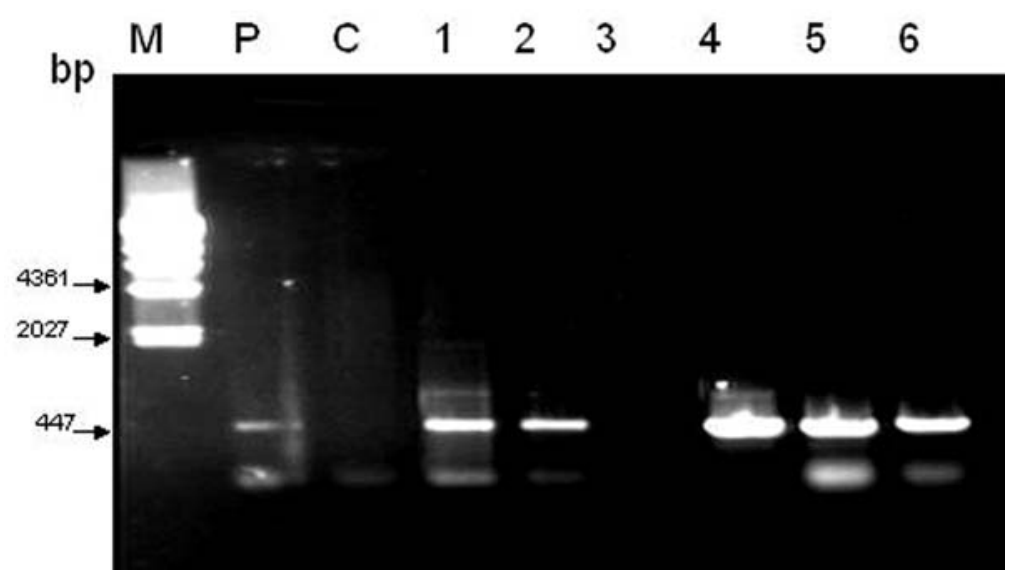

Fig. 4. PCR analysis of putative transgenic plants, DNA primed with oligonucleotides specific to the bar gene. Lane M: DNA molecular weight marker; Lane P: Positive control (plasmid). Lane C: DNA from non-transformed (control) plant. Lanes 1-6: DNA from different primary transformants. Lane 3: Escaped plant.

PCR analysis showed amplifications of 447 bp corresponding to the bar gene, indicating the presence of transgenes in 5 out of 6 putatively transformed plants recovered (Fig. 4). The negative results could be due to non-transformed shoots surviving in the selection medium (Hess et al. 1990, Langridge et al. 1992). When Agrobacterium chromosomal-specific primers were used, no amplification was detected in any of the transgenic materials analyzed (data not shown). This indicated that no residual agrobacteria were present in the analyzed material.

In conclusion, we have developed a simple and reliable genetic transformation system for Echinacea purpurea with bar as selectable marker for the first time. Transformation procedure, involving direct shoot organogenesis, therefore, is rapid to obtain rooted plants and can be of routine use in Echinacea purpurea transformation for studying gene manipulation in this crop and for transferring desirable agronomic traits. 


\section{Reference}

Abbasi BH, Saxena PK, Murch SJ and Liu Chun-Zhao (2007) Echinacea biotechnology: Challenges and opportunities. In Vitro Cell. Dev. Biol. Plant 43: 481-492.

Barrett B (2003) Medicinal properties of Echinacea: A critical review. Phytomedicine, 10: 66-86.

Bauer R (1998) The Echinacea story - the scientific development of an herbal immunostimulant, In: H.D.V. Prendergast, N.L. Etkin, D.R. Harris, P.J. Haughton (Eds.), Plants for Food and Medicine - Modern Treatment and Traditional Remedies, The Royal Botanic Gardens, Kew, pp. 317-332.

Bauer R and Wagner H (1991) Echinacea species as potential immunostimulatory drugs. p. 253-321. In: H. Wagner and N.R. Farnsworth (eds.), Economic and medicinal plant research, Vol. 5. Academic Press.

Bean SJ, Gooding PS, Mullineaux P and Davies DR (1997) A simple system for pea transformation. Plant Cell Reports 16: 513-516.

Choffe KL, Victor JMR, Murch SJ and Saxena PK (2000) In vitro regeneration of Echinacea purpurea L.: Direct somatic embryogenesis and indirect shoot organogenesis in petiole culture. In Vitro Cell Dev. Plant 36(1): 30-36.

Coeugniet EG and Elek E (1987) Immunomodulation with Viscum album and Echinacea purpurea extracts. Onkologie, 27-33.

Gockel, C, Wawrosch CH, Leonhardt W and Kopp, B (1992) Micropropagation of Echinacea angustiofolia. Planta Med. 58: 626-629.

Gómez-Galéra S, Pelacho AM and Gene A (2007) The genetic manipulation of medicinal and aromatic plants. Plant Cell Reports 26: 1689-1715.

Grimm W and Muller H (1999) A randomized controlled trial of the effect of fluid extract of Echinacea purpurea on the incidence and severity of colds and respiratory infections. Am. J. Med. 106: 138-143.

Hanafy M, Pickardt T, Kiesecker H and Jacobsen J (2005). Agrobacterium mediated transformation of faba bean (Vicia faba L.) using embryo axes. Euphytica 142: 227236.

Harbage JF (2001) Micropropagation of Echinacea angustifolia, E. pallida, and E. purpurea from stem and seed explants. Hortic Sci. 36: 360-364.

Hellens RP, Edwards EA, Leyland NR, Bean S and Mullineaux PM (2000) pGreen: a versatile and flexible binary $\mathrm{Ti}$ vector for Agrobacterium-mediated plant transformation. Plant Mol Biol. 42(6): 819-32.

Hess D, Dressler K and Nimmrichter R (1990) Transformation experiments by pippetting Agrobacterium into the spikelets of wheat (Triticum aestivum L.). Plant Sci. 72: 233-24.

Hood EE, Gelvin SB, Melchers LS and Hoekema A (1993) New Agrobacterium helper plasmids for gene transfer to plants. Transgen. Res. 2: 208-218.

Khan MRI, Tabe LM, Heath LC, Spencer D and Higgins TJV (1994) Agrobacterium tumefaciens-mediated transformation of subterranean clover (Trifolium subterraneaneum L). Plant Physiol. 105: 81-88.

Koroch A, Juliani HR, Kapteyn J and Simon JE (2002) In vitro regeneration of Echinacea purpurea from leaf explants. Plant Cell Tiss. Org. Cult. 69: 79-83. 
Koroch A, Kapetyn J, Juliana HR and Simon JE (2003) In vitro regeneration of Echinacea pallida from leaf explants. In Vitro Cell. Dev Biol. Plant. 39: 415-418.

Lakshmanan P, Danesh M and Taji A (2002) Production of four commercially cultivated Echinacea species by different methods of in vitro regeneration, J. Horticult. Sci. Biotechnol. 77: 158-163.

Langridge P, Brettschneider R, Lazzeri P and Lorz H (1992) Transformation of cereals via Agrobacterium and the pollen pathway: a critical assessment. Plant J. 2: 631-638.

Lisowska K and Wysokinska H (2000) In vitro propagation of Catalpa ovata G. Don. Plant Cell Tiss. Org. Cult. 60: 171-176.

Mechanda SM, Baum BR, Johnson DA and Aranson JT (2003) Direct shoot regeneration from leaf segments of mature plants of Echinacea purpurea L. In Vitro Cell Dev. Biol. Plant 39: 505-509.

Pandey V, Misra P, Chaturvedi P, Mishra M, Trivedi P and Tuli R (2010) Agrobacterium tumefaciens-mediated transformation of Withania somnifera (L.) Dunal: an important medicinal plant. Plant Cell Reports 29: 133-141.

Penna S, Sági L and Swennen R (2002) Positive selectable marker genes for routine plant transformation, In Vitro Cell Dev. Biol. Plant 38: 125-128

Percival SS (2000) Use of Echinacea in medicine. Biochem. Pharmacol. 60: 155-158.

Pigeaire A, Abernethy D, Smith PM, Simpson K, Fletcher N, Lu Chin Yi,Atkins CA and Cornish E (1997) Transformation of a grain legume (Lupinus augustifolius L.) via Agrobacterium tumefaciens mediated gene transfer to shoot apices. Mol. Breed. 3: 341-349.

Rong L, Karcher SJ and Gelvin SB (1991) Genetic and molecular analyses of picA, a plant-inducible locus on the Agrobacterium tumefaciens chromosome. J. Bacteriol. 173: 5110-5120.

Sauve RJ , Mmbaga MT and Zhou Suping (2004) In vitro regeneration of the tennessee coneflower (Echinacea tennesseensis). In vitro cell. Dev. Biol. Plant 40: 325-328.

Schroeder HE, Schotz AH,Wardley-Richardson T, Spencer D and Higgins TJV (1993) Transformation and regeneration of two pea cultivars (Pisum satioum L.). Plant Physiol. 101: 751-757.

Sul IW and Korban SS (1996) A highly efficient method for isolating genomic DNA from plant tissues. Plant Tissue Cult. and Biotech. 2(2): 113-116.

Thompson CJ, Movva NR, Tizard R, Crameri R, Davies J E, Lauwereys M and Botterman J (1987). Characterization of the herbicide-resistance bar gene from Streptomyces hygroscopicus. EMBO J. 6: 2519-2523.

Tragni E, Galli CL, Tubaro A, Del Negro P and Della Loggia R (1988) Anti-inflammatory activity of Echinacea angustifolia fractions separated on the basis of molecular weight. Pharm. Res. Commun. 20(suppl): 87-90.

Wang B, Zhang G. Zhu, Chen L and Zhang Y (2006) Genetic transformation of Echinacea purpurea with Agrobacterium rhizogenes and bioactive ingredient analysis in transformed cultures. Colloids and Surfaces B: Biointerfaces 53(1):101-104.

Wang Hsin-Mei and To Kin-Ying (2004) Agrobacterium-mediated transformation in the high-value medicinal plant Echinacea purpurea. Plant Science 166: 1087-1096. 
Wenefrida I, Utomo HS, Meche MM and Nash JL (2007) Inheritance of herbicide resistance in two germplasm lines of Clearfield rice (Oryza sativa L.). Can. J. Plant Sci. 87(3): 659-669.

Yi G, Shin YM, Choe G, Shin B, Kim YS and Kim KM (2007) Production of herbicideresistant sweet potato plants transformed with the bar gene. Biotechnology Letters 29(4): 669-675.

Yoon ES, Jeong JH and Choi YE (2002) Recovery of Basta-resistant Sedum erythrostichum via Agrobactecterium-mediated transformation. Plant Cell Reports 21(1): 70-75.

Zhang Z, Xing A, Staswick $\mathbf{P}$ and Clemente TE (1999). The use of glufosinate as a selective agent in Agrobacterium-mediated transformation of soybean. Plant Cell Tiss. Org. Cult. 56: 37-56. 